\title{
A NOTE ON THE PRESENCE OF MYCOBACTERIUM LEPRAE IN THE CENTRAL NERVOUS SYSTEM OF A MOUSE WITH LEPROMATOUS LEPROSY
}

\author{
M. C. Vaidya, Elisabeth Palmer, G. Weddell and R. J. W. Rees \\ Department of Human Anatomy, University of Oxford, and The National Institute for Medical \\ Research, Mill Hill, London

\section{Plate XIV}

IT has been shown that a disease comparable with lepromatous leprosy in man can be produced in mice by infecting them with Mycobacterium leprae after reducing their immunological capacity by thymectomy and total body irradiation (Rees et al., 1967). Histopathologically, the lesions in mice are identical with those found in untreated patients; moreover, the sites most severely infected are the same as those commonly affected by leprosy in man. During our studies of mouse leprosy and in the course of an examination of selected tissues from one such animal, the central nervous system (CNS) was also investigated. The present paper records our findings.

\section{RESULTS}

The animal chosen had developed nodular swellings on the pads of all four paws and at the bases of both ears $1 \mathrm{yr}$ after infection. It was anaesthetised, rendered hypothermic and killed by cardiac perfusion with a solution of buffered formaldehyde. After perfusion, the tissues were removed and stored in a fresh solution of the fixative at $4^{\circ} \mathrm{C}$. The brain and spinal cord were subsequently embedded in paraffin and cut in a horizontal plane in serial sections at 5 or $7 \mu \mathrm{m}$. Alternate slides were stained with haematoxylin or with methylene blue, then counterstained with cold carbol fuchsin to demonstrate bacilli. The foot-pads, nose, sciatic nerves and popliteal lymph-nodes were also examined and all showed histopathological features typical of fully developed lepromatous leprosy. There were 600 serial sections through the brain, and a systematic examination showed at least one evenly or irregularly stained bacillus in approximately every twentieth section. The bacilli always appear to be intracellular and occur in both the grey and the white matter. Globi of bacilli are attached to the walls of blood vessels, sometimes blocking them. Parasitised blood cells are evident and in fig. 1 they are shown in a section through a blood vessel in the wall of the third ventricle.

Fig. 2 shows another globus in the region of the corona radiata. The few disseminated bacilli in this area presumably came from the degenerating neurone that originally contained the globus. Evenly stained and irregularly stained bacilli are also present in sections of the choroid plexus of the fourth ventricle. In sections of the cerebellum, globi are present in cells of the white and grey matter and a globus containing evenly stained bacilli is present in a Purkinje cell.

In the spinal cord, there are globi in cells of the anterior horn and there is evidence of neural damage. Dorsal root ganglia also contain bacilli. Fig. 3 is an electron micrograph of a ganglion cell containing a group of bacilli close to the nucleus. It is noteworthy that the cytoplasm of this cell appears to be very active and there is no morphological evidence of disturbed cell function. Apart from bacilli, the only abnormal feature is the presence of some curiously shaped vacuoles of uncertain origin, though their derivation from mitochondria cannot be excluded. For comparison, an electron micrograph of a normal ganglion cell is given (fig. 4) and this demonstrates how these cells are related to the capillaries in their neighbourhood. At some places there is very little tissue between the lumen of the vessel and the 


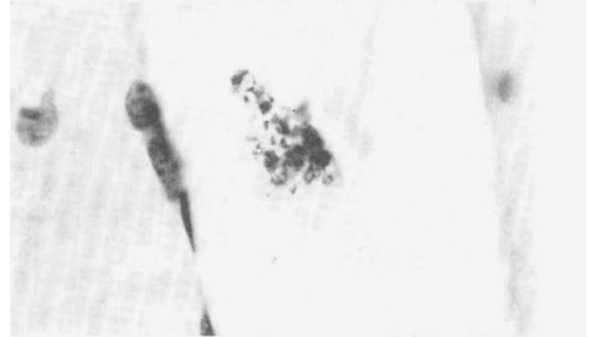

Fig. 1.-A blood vessel in the third ventricle. Bacilli in clot on vessel wall. Haematoxylin and cold carbol fuchsin (HCF). $\times 720$.

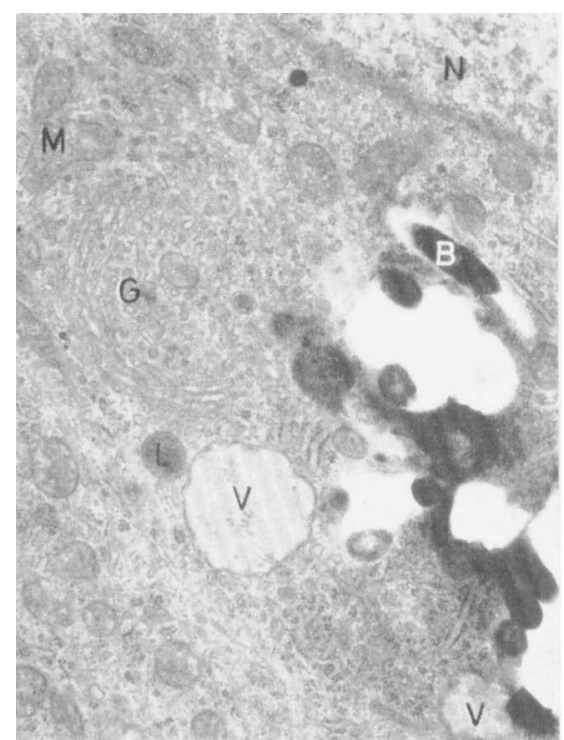

FIG. 3.-Section through a dorsal root ganglion cell showing Myco. Ieprae. $\mathbf{B}=$ Bacilli, $\quad \mathrm{N}=$ nucleus,$\quad \mathrm{G}=$ Golgi membranes, $\mathrm{V}=$ vacuole, $\mathbf{L}=$ lysosome, $\mathrm{M}=$ mitochondrion. Electron micrograph (EM). $\times 13,800$.

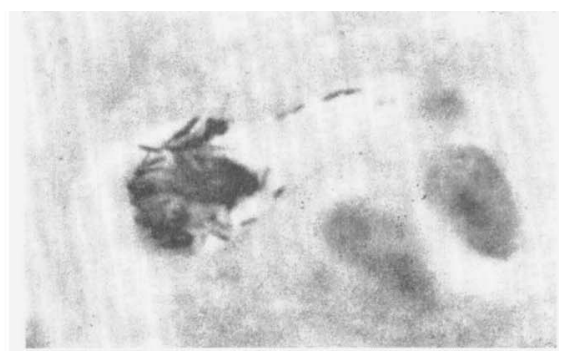

FIG. 2.-Globus of bacilli in a degenerating neurone in the region of the corona radiata. The single organisms probably lie in a process of a damaged nerve cell. HCF. $\times 1200$.

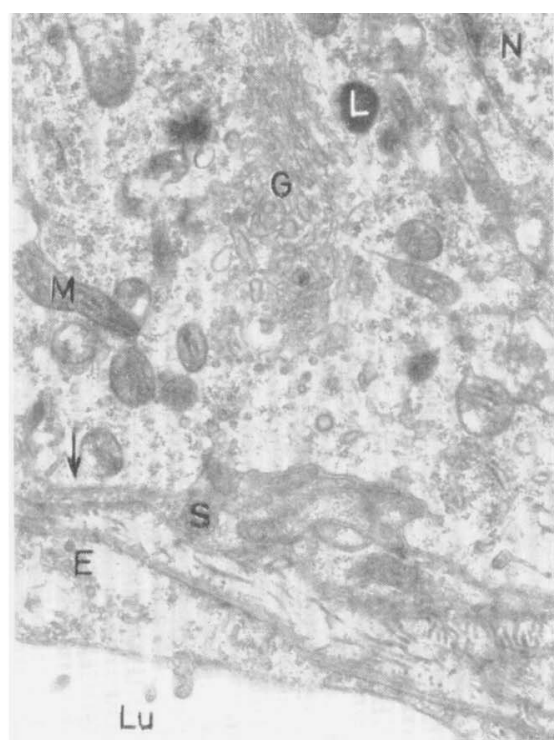

FIG. 4.--Section through an uninfected ganglion cell and wall of neighbouring capillary. $\mathrm{N}=$ Nucleus, $\mathrm{G}=$ Golgi membranes, $\mathbf{L}=$ lysosome, $\mathbf{M}=$ mitochondrion, $\mathrm{Lu}=$ lumen of blood capillary, $\mathrm{E}=$ cytoplasm of endothelial cell lining capillary, $\mathrm{S}=$ ganglion satellite cell. Arrow points to narrow gap between blood vessel and ganglion cell wall. EM. $\times 10,000$. 
cytoplasm of the ganglion cell. This fact, in conjunction with the established presence of bacilli in the lumen of vessels, suggests strongly that the route of entry of bacilli into ganglion cells is from the bloodstream and not, as has been suggested, via the axon (Khanolkar, 1955). It must be conceded that the numbers of organisms in the central nervous system were meagre compared with those found in other tissues.

\section{Discussion}

No clinical symptoms or signs of primary involvement of the central nervous system in leprosy have been reported in the literature as far as we know. The results of a recent electroencephalographic (EEG) study by Alamdarow (1968) indicate that there is a deficient sensory input in severe cases. It also emerged that variations in the EEG patterns of patients with lepromatous leprosy could be correlated with clinical assessments of exacerbation or regression of their disease. A generalised disturbance commonly associated with mental depression also appeared in the EEG tracings of these patients, but this was only indirectly related to the disease. On the other hand, no indication of focal damage to the brain was ever recorded and this corresponds well with the histological observations on the brain of the lepromatous mouse reported above.

Sporadic findings of histopathological changes in the CNS and the presence of bacilli in the brain and spinal cord in leprosy in man were reported at an early date (Danielssen and Boek, 1848) and more systematic studies of involvement of the CNS were published by Sudakewitsch (1888), Uhlenhuth (1900), Monrad-Krohn (1923), Lie (1930), Ermakova (1936) and Lumsden (1964). Most of these authors found bacilli in the spinal cord, dorsal root and cranial nerve ganglia only, but Uhlenhuth saw them also in Purkinje cells of the cerebellum. It is interesting that both he and Monrad-Krohn assumed that infection occurs via the bloodstream.

Three conclusions based on the finding of $M$. leprae in the CNS of the mouse in the present study are of more than academic interest: (1) it seems that $M$. leprae can cross the bloodbrain barrier; (2) the finding of globi of evenly staining organisms indicates that there was sufficient pabulum for their multiplication; and (3) these observations are in accordance with the few recorded accounts of the location of bacilli in the CNS of human patients with lepromatous leprosy. This last fact itself provides further confirmation of the value of the thymectomised and irradiated mouse as a model for the study of human leprosy.

\section{SUMMARY}

Results of a histopathological study of the tissues of a mouse experimentally infected with Mycobacterium leprae indicate that leprosy bacilli can cross the blood-brain barrier and multiply in the brain and that they gain access to ganglion cells by a haematogenous route. The findings are discussed with reference to lepromatous leprosy in man and the use of the thymectomised irradiated mouse as a model for the study of the disease.

\section{REFERENCES}

Alamdarow, I. I. ～～～～～～～1968. Scient. Inst. Study Leprosy, M.O.H., USSR, no. $5(10), 181$.

Danielssen, C. C., AND Boek, W. . 1848. Traité de la Spédalskhed Baillière, 79, pp. 283-285.

ERmakova, Nina

KHANOLKAR, V, R.

1936. Int. J. Leprosy, 4, 325.

LIE, H. P.

1955. Ind. J. Med. Sci., 9, Suppl. 1, p. 7.

1930. Acta path. microbiol. scand., Suppl. 5, p. 32.

Lumsden, C. E. . $\quad$. $\quad$. $\quad$. $\quad$. 1964. In Leprosy in theory and practice, 2nd ed., edited by R. G. Cochrane and T. F. Davey, Bristol, pp. 205-220. 

MonRAD-KROHN, G. H. $\quad$ - . $\quad$. 1923. In The neurological aspect of leprosy ("Spédalskhed "), Christiana, 70, 11- 12.

ReES, R. J. W., WATERS, M. F. R., 1967. Nature, Lond., 215, 599.

Weddell, A. G. M., AND Palmer,

ELISABETH

SUDAKEWITSCH, J.

1888. Beitr. path. Anat., 2, 129.

UHLENHUTH $\quad . \quad$. . . . . . 1900. Dt. med. Wschr., 26, 127.

\title{
ELECTRON MICROSCOPY OF GIARDIA LAMBLIA \\ IN HUMAN JEJUNAL BIOPSIES
}

\author{
S. E. H. Brooks, Johanna Audretsch, C. G. Miller and B. Sparke \\ Departments of Pathology and Paediatrics, University of the West Indies, Mona, \\ Jamaica
}

Plates XV-XIX

DESCRIPTIONS of the fine structure of Giardia lamblia and its relations to the intestinal mucosa are few. Rossi-Espagnet and Piccardo (1957) examined whole mounts of the parasite with the electron microscope without extending descriptions beyond the light-microscope appearances. Cheissen (1964) reported on the ultrastructure of Lamblia duodenalis in rabbits. Takano and Yardley (1965) described Giardia lamblia from human intestinal biopsies and more recently Morecki and Parker (1967) described the ultrastructure of the human Giardia, presenting a case in which the parasite had apparently penetrated the mucosal cells. In both these papers fixation was in osmium tetroxide. Friend (1966) reported in detail the ultrastructure of Giardia muris, for which he used a glutaraldehyde-acrolein fixative with osmium tetroxide post-fixation.

In this paper, we present descriptions of the electron-microscopic appearances of Giardia lamblia, found in jejunal biopsies from three patients and fixed in glutaraldehyde.

\section{METHODS}

Peroral jejunal biopsy was performed with a Watson intestinal biopsy capsule. The biopsy was divided into two parts for light and electron microscopy. The first part was fixed in 4 per cent. formaldehyde and after examination under a dissecting microscope it was embedded in paraffin; sections were stained with haematoxylin and eosin. The other part of the biopsy was fixed for electron microscopy by immediate immersion in 2.5 per cent. glutaraldehyde in $0.1 \mathrm{M}$ phosphate buffer $\left(p \mathrm{H} \mathrm{7.4)}\right.$ at $4^{\circ} \mathrm{C} ; 1-\mathrm{mm}$ pieces were trimmed and fixation was carried out for $2 \mathrm{hr}$. After overnight washing in buffer, the tissues were post-fixed in 1 per cent. phosphate-buffered osmium tetroxide, dehydrated through graded alcohols, passed through propylene oxide, embedded in Maraglas and polymerised at $60^{\circ} \mathrm{C}$ for $18 \mathrm{hr}$. $1-\mu \mathrm{m}$ sections were stained with toluidine blue and examined by light microscopy. Thin sections were cut on an LKB Ultrotome with glass knives and stained with uranyl acetate followed by lead citrate, or lead citrate alone (Reynolds, 1963). Electron microscopy was carried out with a Philips $100 \mathrm{C}$ at $60 \mathrm{kV}$. 